Research Article

\title{
Study on the Aging Time Variation Law of Mechanical Properties of the Laminated Rubber Bearing in Coastal Bridges considering Frictional Slip
}

\author{
Yue Li $\mathbb{D}^{1},{ }^{1}$ Chongming Gao $\mathbb{D}^{1},{ }^{1}$ Chong $\mathrm{Li}^{2}{ }^{2}$ and Qian $\mathrm{Li} \mathbb{D}^{3}$ \\ ${ }^{1}$ College of Civil Engineering, North China University of Technology, Beijing 100144, China \\ ${ }^{2}$ CCCC Highway Bridges National Engineering Research Centre Co., Ltd., Beijing 100088, China \\ ${ }^{3}$ Research Institute of Highway Ministry of Transport, Beijing 100088, China \\ Correspondence should be addressed to Yue Li; liyue@ncut.edu.cn
}

Received 5 June 2021; Revised 24 June 2021; Accepted 6 July 2021; Published 14 July 2021

Academic Editor: Kaiming Bi

Copyright ( 2021 Yue Li et al. This is an open access article distributed under the Creative Commons Attribution License, which permits unrestricted use, distribution, and reproduction in any medium, provided the original work is properly cited.

As an important support member in the structural system of coastal bridges, the frictional slip and the rubber aging of laminated rubber bearings will affect the service safety of the overall structure in earthquakes. In order to investigate the mechanical properties aging law of the rubber bearings considering frictional slip in the coastal bridges, a frictional slip experiment was carried out on the laminated rubber bearings. Moreover, the influence of rubber aging on the mechanical properties of the bearings with various shape coefficients was analyzed by the finite element method during the 100 years of service life of bridges. The results indicate that (1) the horizontal and vertical stiffness of the bearing increase linearly with the aging time of the rubber. The amplification of the bearing stiffness also grows with the shape coefficient of the bearing. (2) The frictional slip initiation displacement of the bearing grows with the rubber aging time. Furthermore, the larger the shape coefficient of the bearing is, the more the frictional slip initiation displacement of the bearing increases. (3) With the increase of the aging time, the equivalent viscous damping ratio of the bearing continues to increase and more energy is consumed by frictional slip. For the bearing with the shape coefficient of 16.38, the equivalent viscous damping ratio at 100 years of rubber aging time is 1.17 times higher than that of the initial state of the bearing, and 33.21\% more energy is consumed through frictional slip. Given that the marine environment accelerates rubber aging and changes the mechanical properties, the effects of the frictional slip and rubber aging properties of the laminated rubber bearings on the seismic dynamic response of bridges should be considered in the seismic design of coastal bridges.

\section{Introduction}

With the extensive construction of coastal roads in countries around the world, laminated rubber bearings have been widely used in coastal bridges [1]. The laminated rubber bearing is constituted by the evenly distributed rubber layers bonded with steel plates, which is the important loading transmission component connecting the girder with the pier in bridges. Under the coupling effect of the coastal environment and service load, the laminated rubber bearing suffered the problems such as steel plate corrosion and rubber aging [2]. At the same time, the laminated rubber bearing is usually placed directly between the girder and the pier without any anchoring in the small- and medium-span bridges. In earthquakes, the unanchored bearings will effectively release the seismic forces and protect the pier by larger shear deformation and frictional slip [3]. In the 2008 Wenchuan Earthquake, there were only 56 piers in the total 2316 piers of simply supported girder bridges that suffered damage in the VII-XI degrees region and the damage rate was $2.4 \%$. However, the damage rate of the bearing reached $16.6 \%$ and the majority is laminated rubber bearings [4].

As the laminated rubber bearing is widely used in highintensity areas in the world, the mechanical properties of the laminated rubber bearing were extensively studied in earthquakes. McDonald et al. $[5,6]$ analyzed the effects of 
vertical forces, support surface roughness and sliding speed on the frictional slip characteristics between the rubber bearing and the supporting member and found that the frictional slip of the bearing has a significant impact on its mechanical properties. Konstantindis et al. [7] investigated the shear performance of the unanchored laminated rubber bearing by the experiment; the results showed that the ultimate shear strain of the bearing can reach $150 \%-250 \%$, after that the bearing will slip. Steelman et al. [8] studied the frictional slip characteristics of a single anchorage laminated rubber bearing (only the top steel plate is anchored) and concluded that the energy dissipation was the most when the friction coefficient between the bearing and the concrete support was $0.25-0.50$. The experiment results provided evidence for the amendment of the bearing provisions in the AASHTO Code. After the 2008 Wenchuan Earthquake, Li et al. $[9,10]$ and Wang et al. [11] confirmed that the frictional slip of the bearings provided seismic isolation effect but increased the risk of girder falling in the simple support girder bridge by the shaking table experiment.

In addition, Itoh et al. [12] found that salt spray, acid mist, and ultraviolet radiation would influence the mechanical properties of the rubber by the durability study on the rubber materials in the coastal environment. The rubber aging will be accelerated by the complex marine environment, which results in the loss of initial elastic properties and the decrease of the loading transferring performance of the laminated rubber bearing [13-17]. Ab-Malek and Stevenson [18] found the mechanical properties deteriorated after testing the rubber materials immersed in seawater for about 42 years. Brown and Butler [19-21] investigated the rubber material in the marine environment from the perspectives of thermal aging and natural aging, respectively. It was found that the mechanical properties of rubber deteriorated after aging; for example, the tensile strength and elongation at break of rubber were both decreased. Yoshito et al. [22] conducted a durability test on the rubber block and confirmed that the marine environment had a great impact on the mechanical properties of the rubber.

Moreover, based on the rubber aging test, Kato et al. [23] conducted a thorough inspection on the material aging characteristics of the rubber bearings used for about 40 years on the offshore Pelham Bridge and found that the horizontal and vertical stiffness of the bearings increased by about $10 \%$ and $6 \%$, respectively. Han et al. [24, 25] determined the basic performance and vertical compression deformation of the rubber bearings after 60 aged years in coastal bridges by conducting experiments on the temperature characteristics of rubber bearings [26]. Tlpakidis [27, 28], Takenaka [29], $\mathrm{Gu}$ and ltoh [30,31], and Chou et al. [32, 33] studied the performance deterioration of rubber bearings from a single marine environmental factor such as thermal aging, ultraviolet radiation, and seawater corrosion, respectively. The results indicated that the rubber aging was accelerated by the complex marine environment, which led to the degradation of the mechanical properties of the rubber bearing and seriously influenced the service time and seismic isolation performance of the rubber bearing.

From the aforementioned literature review, it can be noticed that the frictional slip of the laminated rubber bearing has an important influence on the seismic response of the bridge, and the aging of the rubber material in the coastal environment will further affect the seismic isolation effect of the bearing. The existing research is mainly focused on the mechanical properties of the rubber material and the bearing in the coastal environment. However, little attention has been paid to the effect of the rubber material aging on the mechanical performance of the laminated rubber bearings in coastal bridges considering the frictional slip. Therefore, the effects of the rubber materials aging on the stiffness, frictional slip initiation displacement, energy dissipation capacity, and equivalent viscous damping ratio of the laminated rubber bearing in coastal bridges are analyzed based on the reverse loading test of the laminated rubber bearing and the aging performance theory of the rubber material. Moreover, the influence of the aging of rubber materials on the mechanical performance of the rubber bearings is investigated, which will provide the reference and theory guide for the seismic design of coastal bridges.

\section{Mechanical Properties of the Laminated Rubber Bearing after Material Aging}

The stiffness of the laminated rubber bearing refers to the ability to resist elastic deformation under loading. According to the multinational specification $[34,35]$, the vertical stiffness of the bearing is calculated by the following equation $[36,37]$ :

$$
\begin{aligned}
K_{\mathrm{v}}= & \frac{E_{\mathrm{c}} \times A}{T_{\mathrm{r}}}, \\
E_{\mathrm{c}}= & \frac{E_{\mathrm{ap}} \times E_{\mathrm{\rho}}}{E_{\mathrm{ap}}+E_{\mathrm{\rho}}}, \\
E_{\mathrm{ap}}= & E_{\mathrm{o}} \times\left(1+2 \times k \times S_{1}^{2}\right), \\
E_{\mathrm{o}}= & 3 \times G, \\
k= & 0.97939+0.17734 \times G \\
& -1.4516 \times G^{2}+0.86783 \times G^{2},
\end{aligned}
$$

where $K_{\mathrm{v}}$ is the vertical stiffness of the bearing, $E_{\mathrm{c}}$ is the rubber modified elastic compression modulus, $A$ is the actual vertical load bearing area, $E_{\mathrm{ap}}$ is the apparent elastic modulus of the rubber, $E_{\infty}$ is the bulk modulus of the rubber, $E_{0}$ is the elastic compressive modulus of the rubber, $k$ is the correction factor, $S_{1}$ is the first shape coefficient, and $G$ is the shear modulus of rubber.

The horizontal shear stiffness of the bearing is calculated by the following equation: 


$$
K_{h}=\frac{G \times A}{T_{r}},
$$

where $K_{\mathrm{h}}$ is the horizontal stiffness and $T_{\mathrm{r}}$ is the total rubber layer thickness.

Due to the complex molecular properties of the rubber material, Mooney [38] has proposed the large elastic deformation theory of rubber based on the strain energy functions in 1940 to more accurately describe the elastic constitutive behaviors of rubber. The theory assumes that (1) the rubber is isotropic and incompressible $(0.48 \leq \mu \leq 0.5)$ superelastic body; (2) the rubber follows Hooke's law in shear deformation and superimposed shear in a plane perpendicular to the unidirectional tensile or compressive axis. Based on the assumption, the rubber strain energy function $W$ is defined here as follows [39-41]:

$$
W=C_{10}\left(\lambda_{1}^{2}+\lambda_{2}^{2}+\lambda_{3}^{2}-3\right)+C_{01}\left(\lambda_{1}^{-2}+\lambda_{2}^{-2}+\lambda_{3}^{-2}-3\right),
$$

where $\lambda_{1}, \lambda_{2}$, and $\lambda_{3}$ are side elongations of the rubber cube and $C_{10}$ and $C_{01}$ are the positive definite constants for rubber materials.

From the mathematical point of view, Rivlin [42] has obtained the general expression for the strain invariant considering the general form of the strain energy function, as follows:

$$
\begin{aligned}
& I_{1}=\lambda_{1}^{2}+\lambda_{2}^{2}+\lambda_{3}^{2}, \\
& I_{2}=\lambda_{1}^{2} \lambda_{2}^{2}+\lambda_{2}^{2} \lambda_{3}^{2}+\lambda_{1}^{2} \lambda_{3}^{2}, \\
& I_{3}=\lambda_{1}^{2} \lambda_{2}^{2} \lambda_{3}^{2} .
\end{aligned}
$$

Based on the incompressibility of the rubber material and the volume invariance in deformation, the relation $I_{3}=1$ is introduced, so that only two of the three strain invariants are independent, as follows:

$$
\begin{aligned}
& I_{1}=\lambda_{1}^{2}+\lambda_{2}^{2}+\lambda_{3}^{2}, \\
& I_{2}=\lambda_{1}^{-2}+\lambda_{2}^{-2}+\lambda_{3}^{-2},
\end{aligned}
$$

where $I_{1}$ and $I_{2}$ are determined by the stretching ratio of the three main axes. Thus, the strain energy function $W$ corresponding to the isotropic incompressible material can be expressed as $W=\left(I_{1}, I_{2}, I_{3}\right)$. Then, Mooney's rubber strain energy function is described as follows:

$$
W=C_{10}\left(I_{1}-3\right)+C_{01}\left(I_{2}-3\right) .
$$

Equation (10) is the Mooney-Rivlin model widely used in the study of the deformation of the elastomer, which reflects the mechanical properties of rubber.

However, on coastal bridges, rubber aging is extremely serious due to the long-term complex and harsh marine environment. Based on the thermal aging experiment of rubber materials, the time-varying laws of the constants $C_{10}$ and $C_{01}$ in the Mooney-Rivlin model for rubber materials are obtained as shown in equations (11) and (12) [43, 44]. Derived from equations (11) and (12), the material constants for every 10 aging years are shown in Table 1, and the variation curves are shown in Figure 1.

$$
\begin{aligned}
& C_{10}=0.0015 n+0.4054, \\
& C_{01}=0.0004 n+0.2165,
\end{aligned}
$$

where $n$ is the actual aging time and the unit is year.

Then, the expressions between the mechanical properties and aging time of the laminated rubber bearings are obtained as follows [36]:

$$
\begin{aligned}
& \frac{K_{v}(t)}{K_{v}(0)}=0.0027 \times t+1.0021, \\
& \frac{K_{h}(t)}{K_{h}(0)}=0.0052 \times t+0.996,
\end{aligned}
$$

where $K_{\mathrm{v}}(t)$ is the vertical stiffness corresponding to the aged time $t, K_{\mathrm{v}}(0)$ is the initial vertical stiffness, $K_{\mathrm{h}}(t)$ is the horizontal stiffness corresponding to the aged time $t$, and $K_{\mathrm{h}}$ $(0)$ is the initial horizontal stiffness.

\section{Mechanical Performance Experiments of the Laminated Rubber Bearings}

As the laminated rubber bearings are always put on the piers without any connection with the girders in small and medium-span bridges, the frictional slip performance of the bearings was investigated under various axial pressures by the cyclic loading test. The test results are the basis of the investigation of the seismic mechanical properties of the aged laminated rubber bearing in the coastal environment. The loading device is shown in Figure 2 and the test conditions are shown in Table 2.

In order to realistically reflect the working condition of the bearing, the top surface of the bearing is anchored with the loading device through the connection plate under a constant vertical load. The bottom rubber layer of the bearing will slide on the support surface. The deformation of the bearing is shown in Figure 3 during the loading process.

The relationship between the friction force and the loading displacement is shown in Figure 4. It can be found that the friction will convert from static friction to sliding friction with the increase of the displacement. The friction coefficient is inversely proportional to the compressive stress (as shown in Figure 5) and decreases from 0.31 to 0.15 when the vertical pressure grows from $4 \mathrm{MPa}$ to $10 \mathrm{MPa}$.

To investigate the effect of rubber aging on the mechanical properties, the finite element models of the laminated rubber bearing were established in ABAQUS. The bearing was put on the supporting rigid block, as shown in Figure 6(a).

The eight-node linear brick reduced integral three-dimensional solid element was adopted to simulate the steel plate layer of the bearing whose elastic modulus is 2.0E5 MPa and Poisson's ratio is 0.3. To precisely describe the mechanical properties, the Mooney-Rivlin model was 
TABLE 1: Mooney-Rivlin parameters.

\begin{tabular}{ccccccccccccc}
\hline \multicolumn{2}{c}{ Aging time (years) } & 0 & 10 & 20 & 30 & 40 & 50 & 60 & 70 & 80 & 90 & 100 \\
\hline \multirow{2}{*}{ Material constants } & $C_{10}(\mathrm{MPa})$ & 0.405 & 0.420 & 0.435 & 0.450 & 0.465 & 0.480 & 0.495 & 0.510 & 0.525 & 0.540 & 0.555 \\
& $C_{01}(\mathrm{MPa})$ & 0.202 & 0.221 & 0.225 & 0.229 & 0.233 & 0.237 & 0.241 & 0.245 & 0.249 & 0.253 & 0.257 \\
\hline
\end{tabular}

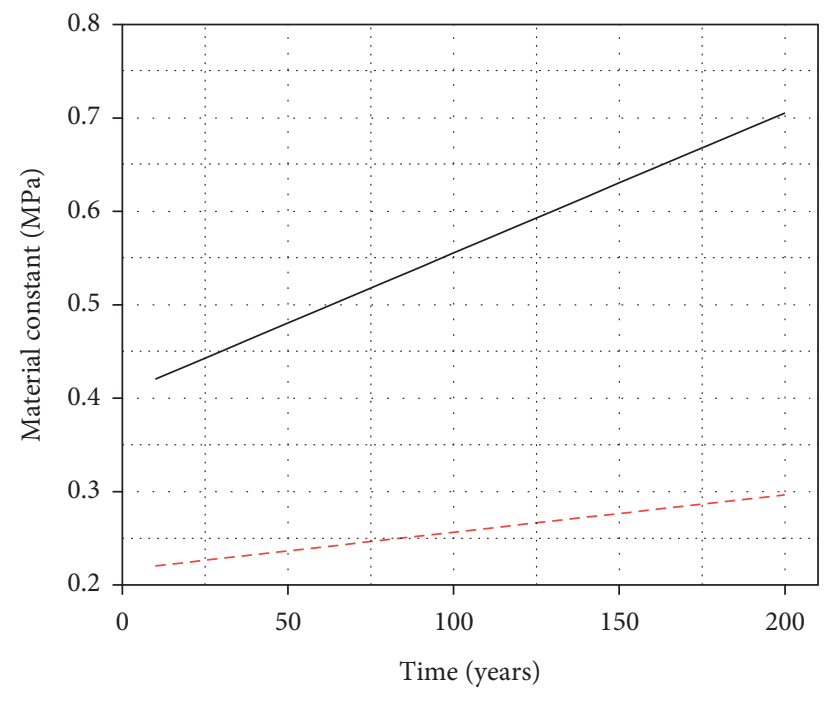

$-\mathrm{C}_{10}$

Figure 1: Trend curves of $C_{10}$ and $C_{01}$.

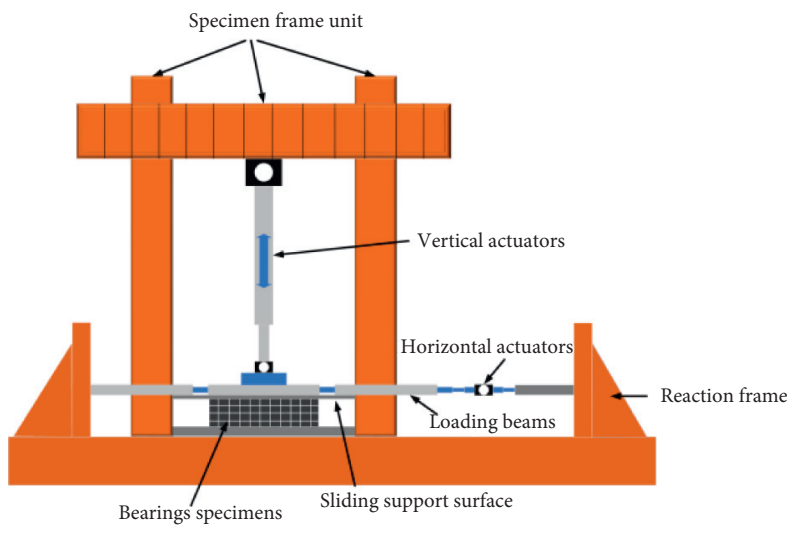

Figure 2: Specimen loading diagram.

TABLE 2: Test parameters of bearings.

\begin{tabular}{lcccc}
\hline Serial number & Bearing type & Total rubber thickness $(\mathrm{m})$ & Shape coefficient & Vertical load $(\mathrm{MPa})$ \\
\hline B1 & GJZ $500 \times 550 \times 78$ & 0.048 & 16.38 & 4 \\
B2 & GJZ $500 \times 550 \times 78$ & 0.048 & 16.38 & 6 \\
B3 & GJZ $500 \times 550 \times 78$ & 0.048 & 16.38 & 8 \\
B4 & GJZ $500 \times 550 \times 78$ & 0.048 & 16.38 & 10 \\
\hline
\end{tabular}

Notes: (1) the bearing design should meet the requirements of the "Series of Elastomeric Pad Bearings for Highway Bridges" (JT/T663-2006) [45]; (2) the vertical compressive stresses of the bearings should meet the requirements of the "Specifications for Design of Highway Reinforced Concrete and Prestressed Concrete Bridges and Culverts" (JTG3362-2018) [46]. 


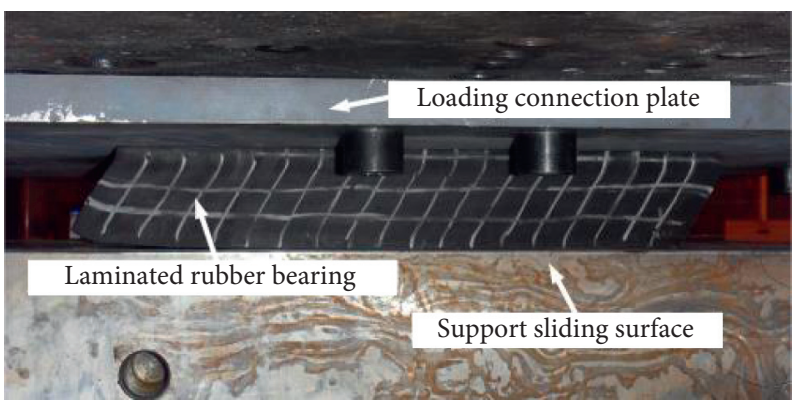

FIgURE 3: Specimen in the friction sliding test.

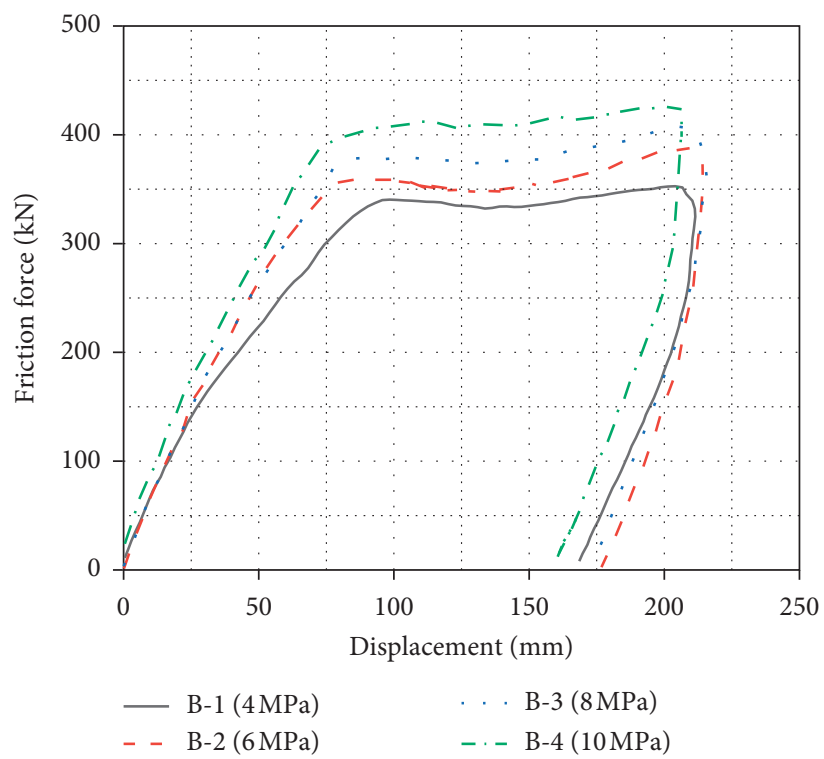

FIgURE 4: Relationship of friction force and displacement.

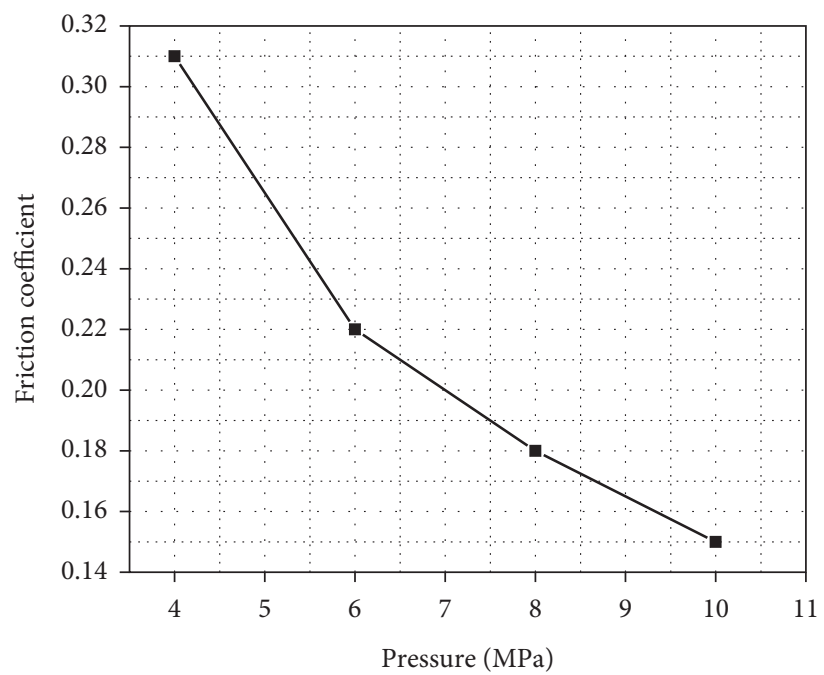

FIgURE 5: Relationship of friction coefficient and pressure.

adopted to simulate the rubber material, and the intrinsic constants of the material were taken from Table 1 corresponding with aging time. The rubber layers were meshed by the eight-node linear brick reduced integral hybrid three- dimensional solid element. Additionally, a mesh convergence analysis was carried out to explore the appropriate mesh size. The results suggested that the bearing with a mesh size of about $20 \mathrm{~mm}$ can effectively simulate the performance 


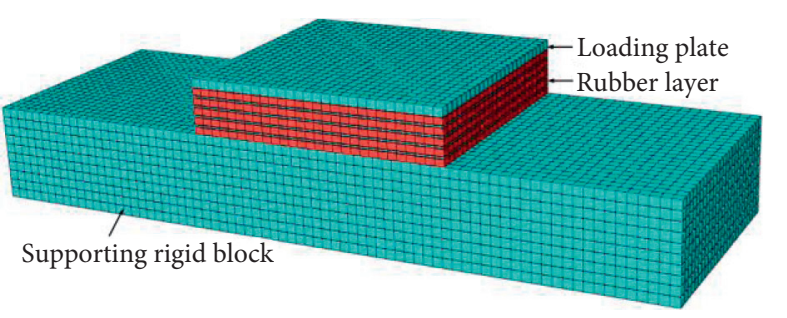

(a)

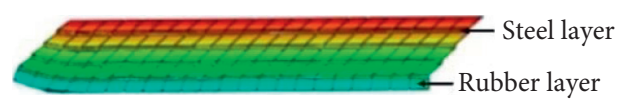

(b)

FIGURE 6: Finite element model and deformation of bearing. (a) Finite element model of the bearing. (b) Shear deformation of bearing.

of the studied bearing with an appropriate time-consuming. The tied constraint was used between each steel plate layer and rubber layer.

To model the surface interaction between the bottom rubber layer of the bearing and the top layer of the supporting rigid block, the classical Coulomb friction model and the contact pressure model were designated the tangential and normal directions to the contact surfaces, respectively. Based on previous studies [3], the friction coefficient between the contact surface of the rubber and steel plate was set as 0.3 , which is also adopted in the code [45]. All nodes on the top endplate of the bearing were constrained to a reference point at the centroid that was restrained against rotation but allowed to translate vertically and in one direction laterally. Similarly, all nodes on the bottom surface of the supporting rigid block were constrained against translation and rotation in all degrees of freedom. The deformation of the bearing is illustrated in Figure 6(b).

The friction sliding hysteresis curves of the bearing obtained from the finite element model are compared with the test results, as shown in Figure 7 (taken specimen B-1 under a vertical pressure of $6 \mathrm{MPa}$ as an example). It can be found that the simulation results agree well with the experimental results. In addition, the damping ratio, energy dissipation, equivalent stiffness, and friction coefficient are compared with the test results for different equivalent shear deformations after frictional slip of the bearing, as shown in Table 3 . At the early loading stage, when the shear deformation is $100 \%$, the bearing does not slip, and the energy dissipation is minor, so there is a numerical error in the damping ratio and energy dissipation, and the deviation between the experimental and numerical results is $27 \%$. However, after the shear deformation beyond $100 \%$, the energy dissipation of the bearing keeps increasing, and the deviations of the damping ratio and the energy dissipation between the experimental and numerical results are within $10 \%$. At this time, the deviation of the equivalent stiffness is only $2.5 \%$ at $200 \%$, and the deviation of the friction coefficient is $9.3 \%$ at $300 \%$. According to the experimental and numerical results shown in Figure 7 and Table 3, it can be verified that the finite element model could better reflect the mechanical properties of the bearings under the horizontal recycling load.

\section{Influence of Rubber Aging on the Mechanical Properties of Laminated Rubber Bearings}

In earthquakes, the frictional slip of the laminated rubber bearing and the aging time of the rubber material will have a significant impact on the seismic performance of the coastal bridge $[3,37]$. Therefore, the influence of the rubber aging time on the horizontal and vertical stiffness, frictional slip initiation displacement, and energy dissipation capacity of laminated rubber bearings with four shape coefficients is analyzed, and the bearing parameters are shown in Table 4 .

\subsection{Effect of Rubber Aging on the Stiffness of Laminated Rubber} Bearings with Four Shape Coefficients. Figure 8 shows the relationship between the rubber aging time and the horizontal and vertical stiffness of the bearings with four shape coefficients. It can be found that the horizontal and vertical stiffness of the bearing is increased linearly with the rubber aging time.

For the specimen P-1 with a shape coefficient of 16.38 , the maximum difference of the horizontal stiffness between the aging 100 years and the initiation reaches $34.3 \%$, and the maximum difference of the vertical stiffness is $23.48 \%$. Moreover, the stiffness growth rate is increasing with the aging time for the larger shape coefficient of the bearing.

\subsection{Effect of Aging Time on the Frictional Slip Initiation} Displacement of the Bearings. The friction slip initiation displacement of the laminated rubber bearing is an important reference after which the stage will convert from the controlled static friction to the uncontrolled sliding friction in a horizontal earthquake, which has a great impact on the displacement control of the girder. Therefore, in the service life of the bridge, the effect of rubber aging time on the frictional slip initiation displacement of the bearings with four shape coefficients is analyzed when the shear deformation reaches $300 \%$, as shown in Figure 9. It can be found that the initial sliding displacement of the bearing increases with the aging time. At the same time, the larger shape coefficient bearing also has a greater initiation displacement. Therefore, for the bridges with laminated rubber bearings located at the coastal areas, more attention should be paid to controlling the displacement of the girders in earthquakes 


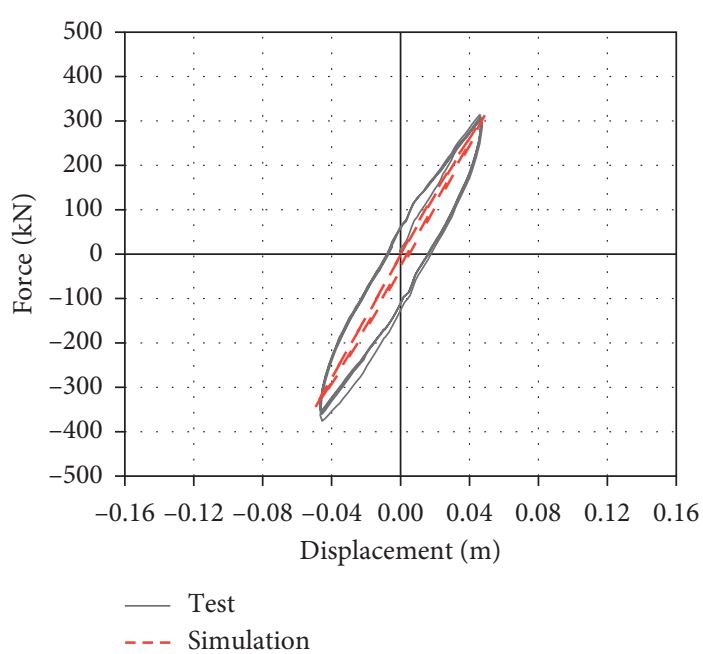

(a)

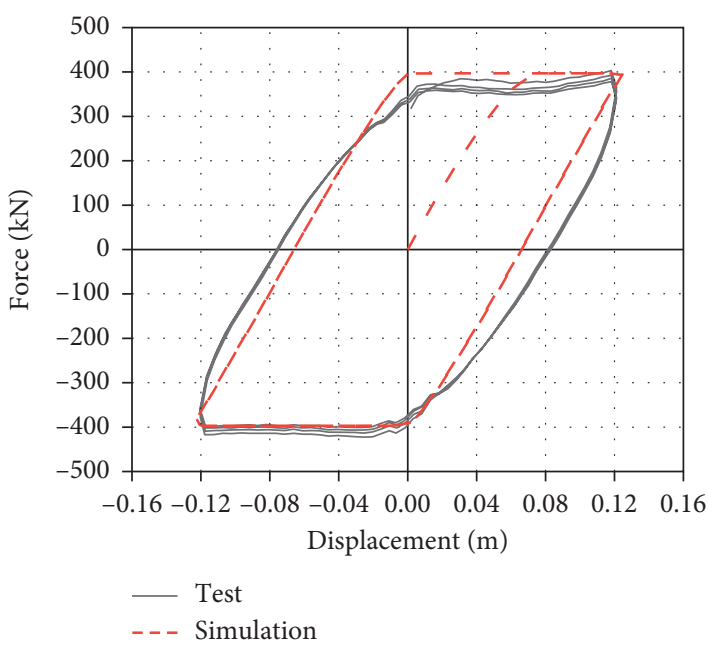

(c)

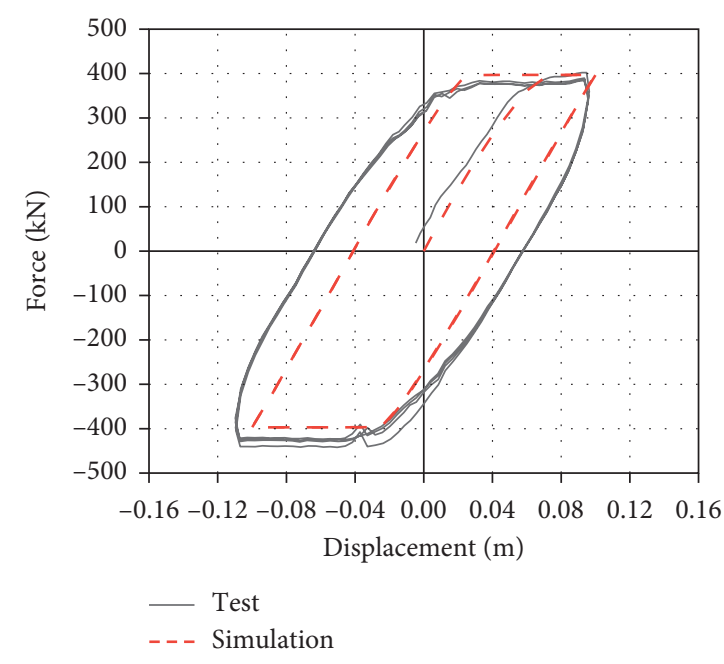

(b)

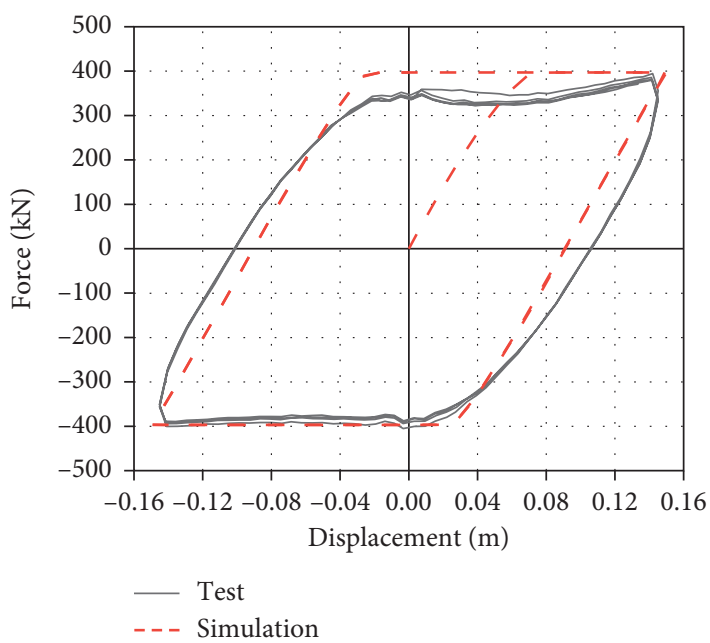

(d)

Figure 7: Comparison of bearing force-displacement relationship curves under horizontal recycling load (6 MPa): (a) 100\%, (b) 200\%, (c) $250 \%$, and (d) $300 \%$.

TABLE 3: Comparison of numerical and test results.

\begin{tabular}{lccccccccc}
\hline \multirow{2}{*}{ Equivalent shear deformation (\%) } & \multicolumn{2}{c}{ Damping ratio (\%) } & \multicolumn{2}{c}{$\begin{array}{c}\text { Energy dissipation } \\
(\mathrm{kN} \cdot \mathrm{m})\end{array}$} & \multicolumn{2}{c}{$\begin{array}{c}\text { Equivalent stiffness } \\
(\times 104 \mathrm{kN} / \mathrm{mm})\end{array}$} & \multicolumn{2}{c}{ Friction coefficient } \\
& Test & Simulation & Test & Simulation & Test & Simulation & Test & Simulation \\
\hline 100 & 3.10 & 4.25 & 3.45 & 2.51 & 0.62 & 0.61 & 0.220 & 0.221 \\
200 & 25.22 & 23.88 & 35.11 & 31.96 & 0.40 & 0.39 & 0.211 & 0.213 \\
250 & 34.94 & 31.85 & 52.14 & 51.73 & 0.32 & 0.32 & 0.193 & 0.208 \\
300 & 40.21 & 37.15 & 72.67 & 71.59 & 0.26 & 0.26 & 0.182 & 0.199 \\
\hline
\end{tabular}

TABLE 4: Bearing model parameters.

\begin{tabular}{lcccc}
\hline Model number & Bearing type & Total rubber thickness $(\mathrm{m})$ & Number of rubber layers & Shape coefficient \\
\hline P-1 & GJZ $500 \times 550 \times 60$ & 0.04 & 5 & 5 \\
P-2 & GJZ $500 \times 550 \times 80$ & 0.05 & 5 & 16.38 \\
P-3 & GJZ $500 \times 550 \times 80$ & 0.06 & 5 & 13.10 \\
P-4 & GJZ $500 \times 550 \times 95$ & 0.075 & 5.91 \\
\hline
\end{tabular}

Notes: the design of the bearing shape coefficient meets the requirements of the "Specification for the Design of Highway Reinforced Concrete and Prestressed Concrete Bridges and Culverts" (JTG3362-2018) [46]. 


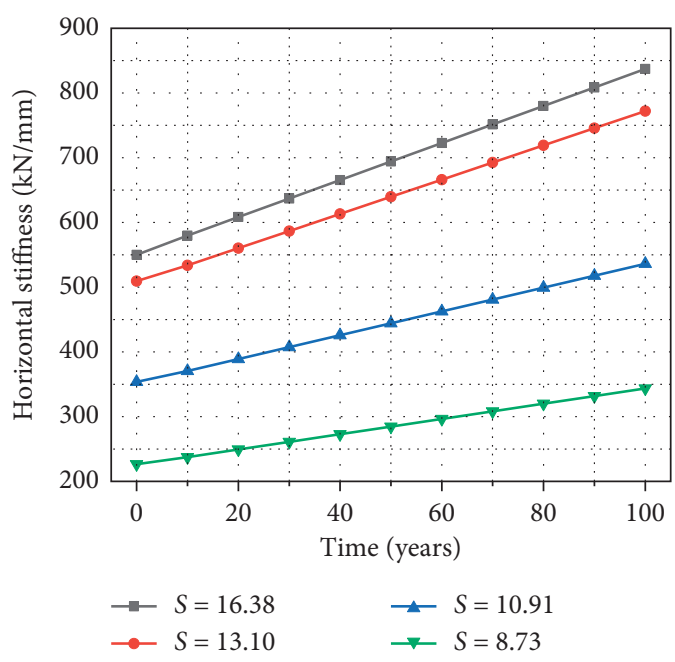

(a)

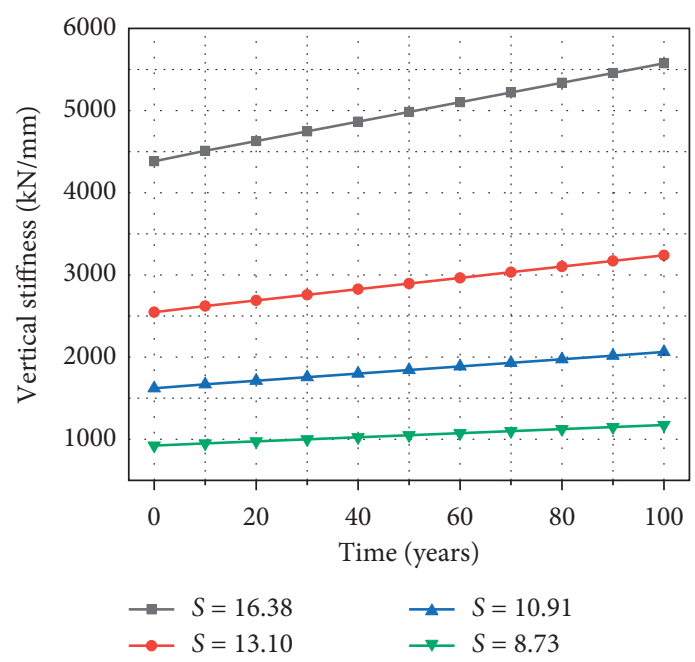

(b)

Figure 8: Effect of aging time on the bearing stiffness. (a) Horizontal stiffness. (b) Vertical stiffness.

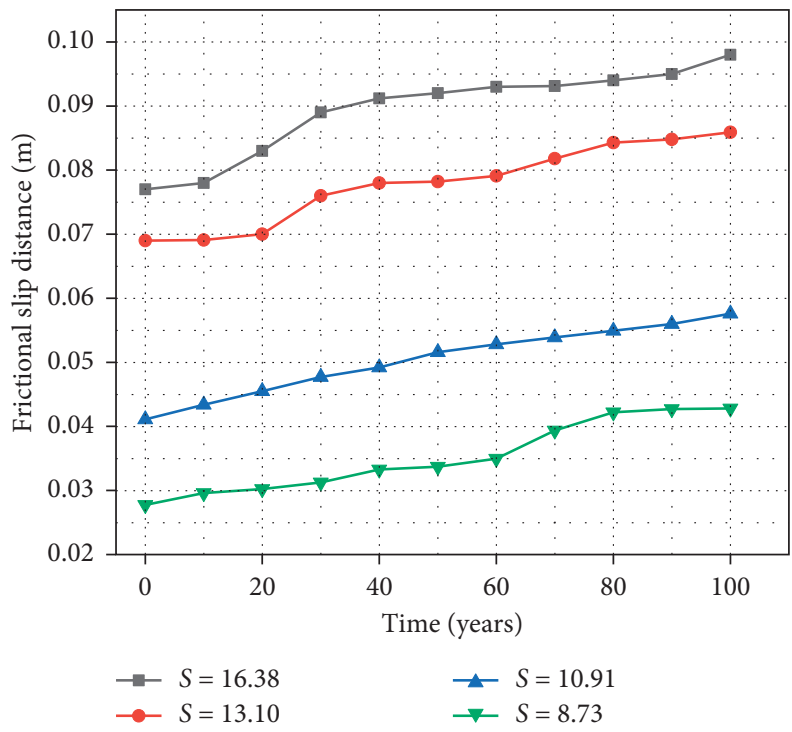

Figure 9: Effect of aging on the frictional slip distance of the bearings.

and preventing the girder from falling. At the same time, for the bearing with a smaller shape coefficient, the initial sliding displacement is also smaller. Namely, for the bearing with a thicker rubber layer, the displacement of the girder is smaller when the bearing enters the sliding state. Therefore, when the high bearings are used in the bridge, more attention should be paid to the seismic damage due to the bearing slip.

4.3. Effect of Aging Time on the Frictional Slip Performance of the Laminated Rubber Bearings. The force and displacement hysteresis curves of the bearings are compared in the initial state, the aging for 50 years, and the aging for 100 years. Taking the shear deformation of $300 \%$ as an example (as shown in Figure 10), the horizontal force and displacement hysteresis curve of the bearing is fuller with the rubber aging time increasing. At each rubber aging stage, the larger the shape coefficients of the bearings, namely, the thinner the rubber layer, the fuller the force and displacement hysteresis curve of the bearing under horizontal load, as shown in Figure 11. It is mainly because the thinner the rubber layer is, the greater the horizontal stiffness is, the earlier the bearing enters the frictional slip stage. Therefore, for the bridges in the marine environment, it is necessary to consider the influence of the bearing friction slip on the seismic performance of the bridge to avoid the girder falling when the shape coefficient of the laminated rubber bearing is smaller.

From the relationship between the aging time of rubber material and the energy consumption by the frictional slip of the bearing (as shown in Figure 12), it can be found that the dissipated energy by the friction slip of the bearing will be more with the aging time increasing. For the bearing with a 


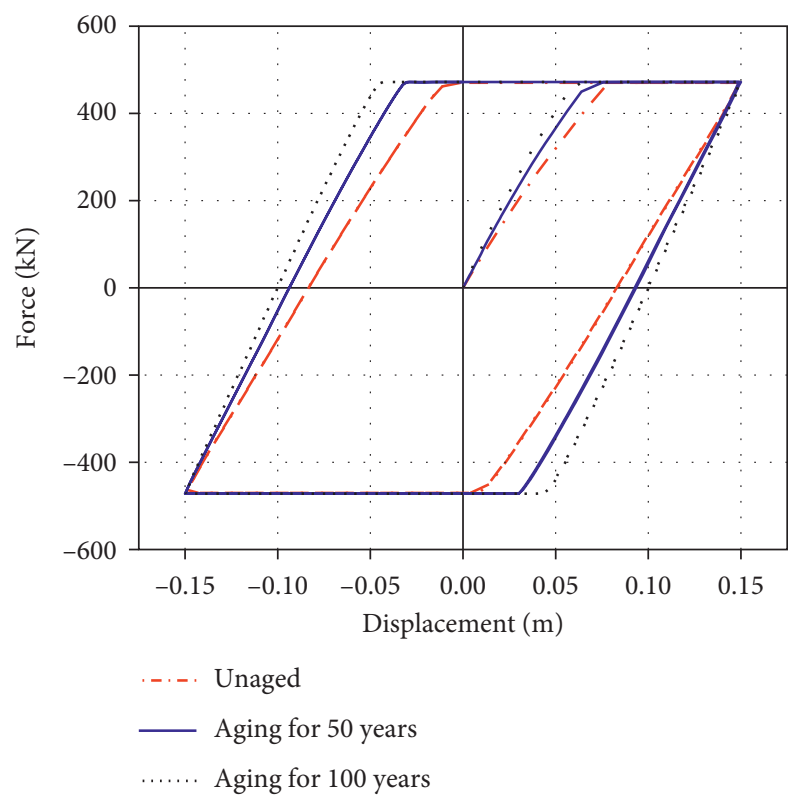

FIGURE 10: Effect of rubber aging on the hysteresis performance of bridge laminated rubber bearing (4MPa).
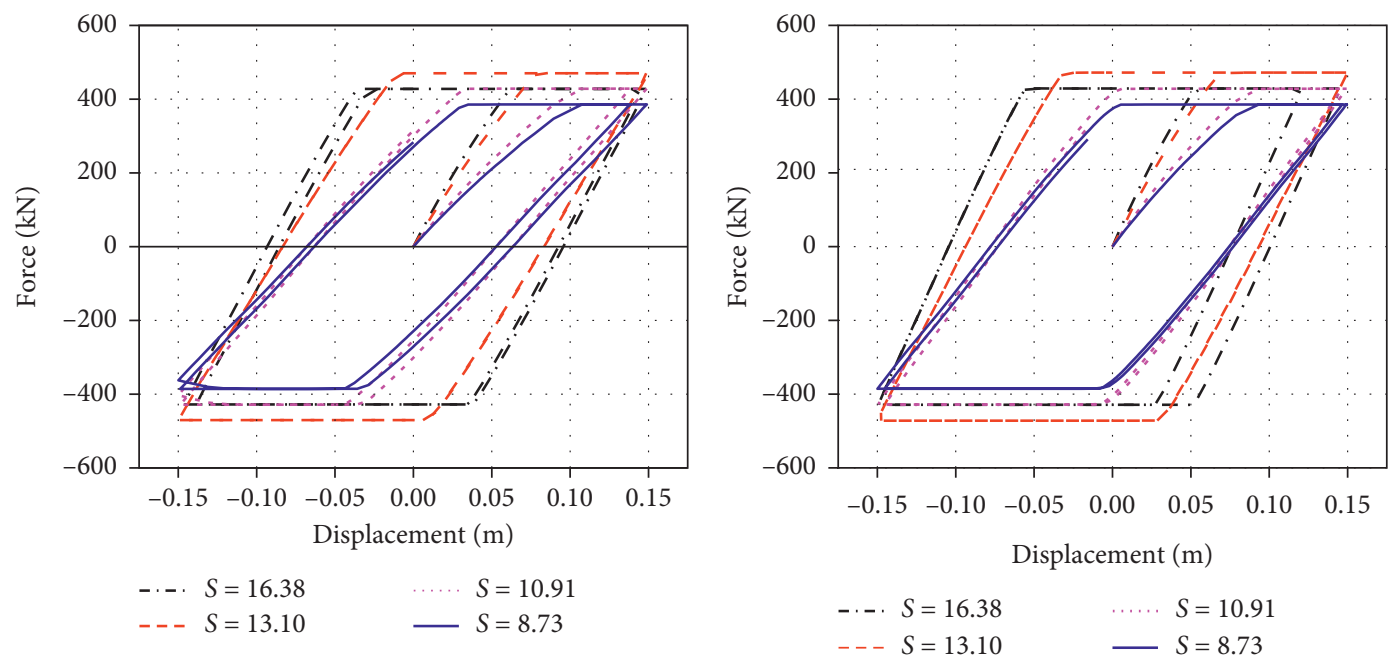

(a)

(b)

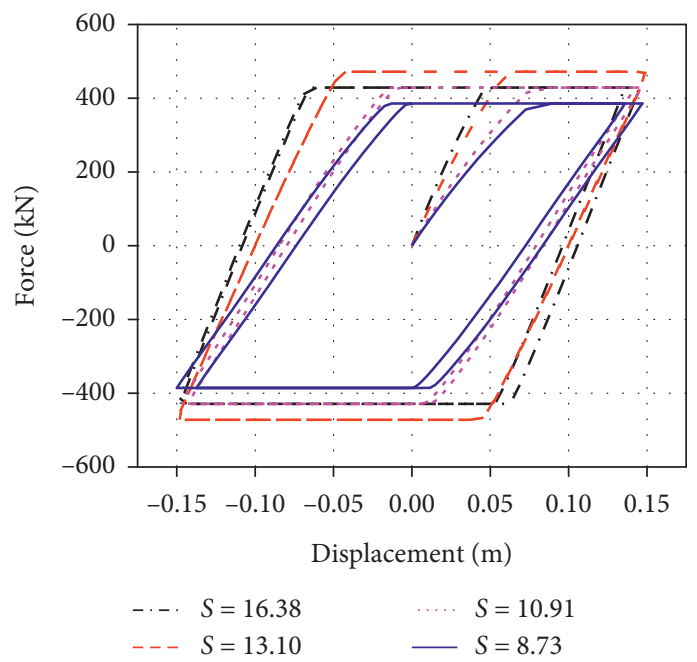

(c)

FIGURE 11: Effect of aging time on the hysteresis performance of the laminated rubber bearing (4 MPa): (a) initial state; (b) aging for 50 years; (c) aging for 100 years. 


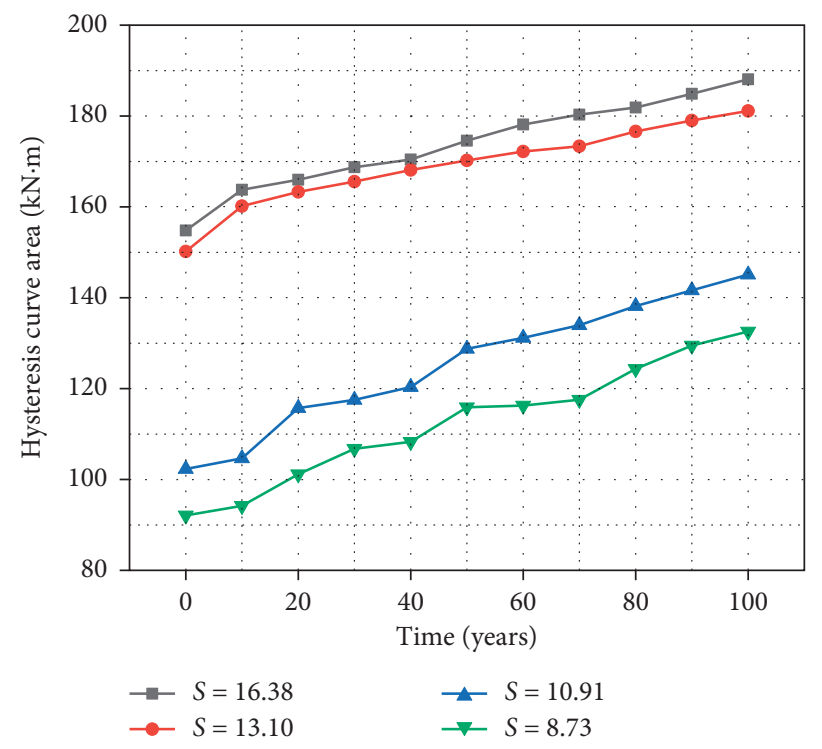

FIGURE 12: Effect of aging time on energy dissipation of the bearing.

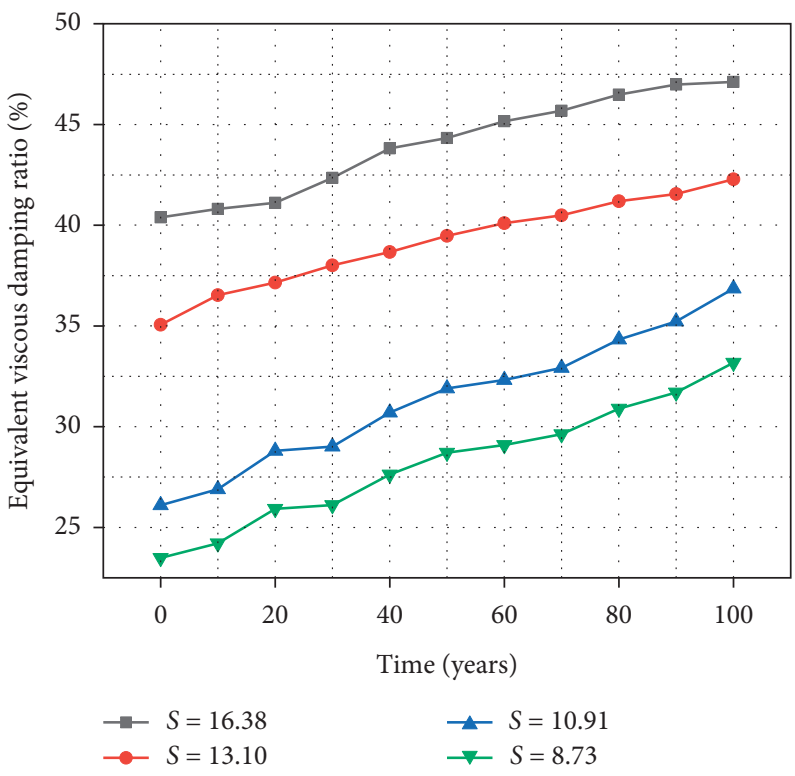

FIGURE 13: Effect of aging time on the equivalent viscous damping ratio of the bearing.

16.38 shape coefficient, the rubber material aging for 100 years dissipated $33.21 \%$ more energy than that of the initial state by frictional slip. When the rubber aging time is 100 years, the bearing with a shape coefficient of 16.38 dissipated $41.87 \%$ more energy by frictional slip than the bearing with a shape coefficient of 8.73 .

Meanwhile, from the relationship curve between the rubber aging time and the equivalent viscous damping ratio of the bearing as shown in Figure 13, it can be concluded that the equivalent viscous damping ratio of the bearing increases with the aging time. For the bearings with the shape coefficients of 16.38 and 8.73 , the equivalent viscous damping ratios of the rubber 100 years aging time are 1.17 times and 1.40 times that of the bearing initial state. Moreover, the shape coefficient has a large effect on the equivalent viscous damping ratio of the bearing. When the rubber aging time reaches 100 years, the equivalent viscous damping ratio of the bearing with the shape coefficient of 16.38 is 1.42 times the bearing with the shape coefficient of 8.73 .

\section{Conclusions}

Earthquake experience shows that the frictional slip of the bearing and the aging of the rubber material will have a significant impact on the seismic mechanical properties of the laminated rubber bearings in coastal bridges. Based on the frictional slip experiment, the effect of the rubber material aging on the mechanical performance of the laminated 
rubber bearings in coastal bridges was studied, and the main conclusions are as follows:

(1) The horizontal and vertical stiffness of the laminated rubber bearing increases linearly with the growth of rubber aging time. For the bearing with a shape coefficient of 16.38, the maximum differences between the horizontal and vertical stiffness of the bearing after 100 years of aging are $34.3 \%$ and $23.8 \%$ of the initial state, respectively. Moreover, the larger the shape coefficient is, the greater the bearing stiffness increases with the aging time of rubber material.

(2) Considering the frictional slip, the initial sliding displacement of the bearing increases with the growth of the aging time. Moreover, the larger the shape coefficient of the bearing is, the quicker the initial displacement of the frictional slip increases.

(3) With the growth of aging time, the dissipation energy is also increased by the frictional slip. For the bearing with a shape coefficient of 16.38 , the dissipation energy by frictional sliding of the bearing with the 100 years of aging is $33.21 \%$ that of the bearing in initial state. When the aging time of rubber materials reaches 100 years, the bearing with the shape coefficient of 16.38 dissipates $41.87 \%$ more energy by frictional sliding than that of the bearing with the shape coefficient of 8.73 .

(4) With the growth of aging time, the equivalent viscous damping ratio of the bearing also increases. For the bearing with the shape coefficients of 16.38 and 8.73 , the equivalent viscous damping ratio of the bearing with 100 years aging time is 1.17 times and 1.40 times that in the initial state. Moreover, the larger the shape coefficient of the bearing is, the quicker the equivalent viscous damping ratio increases.

(5) As the rubber aging has a significant impact on the seismic response of the laminated rubber bearings, the effect of the rubber aging time and the shape coefficient of the bearings on the service life in the seismic areas with significant marine erosion environment should be considered.

\section{Data Availability}

The experimental data used to support the findings of this study are included within the article.

\section{Conflicts of Interest}

The authors declare that there are no conflicts of interest regarding the publication of this study.

\section{Acknowledgments}

This work was financially supported by the National Natural Science Foundation of China (Grant nos. 51408009 and 51608010), Fundamental Research Funds for the Beijing's
Universities (110052971921/062), and Yuyou Talent Project of North China University of Technology (Grant no. XN012/ 044).

\section{References}

[1] L. Lan, "Analysis on construction of cross-sea bridge in China," Transportation World, vol. 19, no. 4, pp. 24-30, 2012.

[2] J. Li, T. Peng, and Y. Xu, "Damage investigation of girder bridges under the Wenchuan earthquake and corresponding seismic design recommendations," Earthquake Engineering and Engineering Vibration, vol. 7, no. 4, pp. 337-344, 2008.

[3] K. H. Wang, G. Wu, and P. P. Zhang, "Experimental study on frictional slip performance of plate rubber bearing," Vibration and Shock, vol. 39, no. 19, pp. 1-6, 2020.

[4] W. L. Zhuang and L. S. Chen, Seismic Damage Analysis of Highway in Wenchuan Earthquake - Bridges and Tunnels, People's Traffic Publishing House, Beijing, China, 2013.

[5] J. Mcdonald, E. Heymsfield, and R. R. Avent, "Slippage of neoprene bridge bearings," Journal of Bridge Engineering, vol. 5, no. 3, pp. 216-223, 2000.

[6] I. Schrage, Anchoring of Bearings by Friction, Special Publication SP70-12, American ConcreteInstitute, Detroit, MI, USA, 1981.

[7] D. Konstantindis, J. M. Kelly, and N. Makris, Experimental Investigations on the Seismic Response of Bridge Bearings, Earthquake Engineering Research Center, Berkeley, CA, USA, 2008.

[8] J. S. Steelman, L. A. Fahnestock, E. T. Filipov et al., "Shear and friction response of non-seismic laminated elastomeric bridge bearings subject to seismic demands," Journal of Bridge Engineering, vol. 18, no. 4, pp. 612-623, 2013.

[9] J. Z. Li, H. Tang, and Z. G. Guan, "Shake table test and numerical analysis of a bridge model supported on elastomeric pad bearings," Journal of Earthquake Engineering, vol. 21, no. 4, pp. 23-41, 2017.

[10] H. Tang and J. Z. Li, "Displacement control method for continuous bridges on laminated rubber bearings under earthquake excitation," China Journal of Highway and Transport, vol. 26, no. 3, pp. 110-116, 2013.

[11] K. R. Wang, X. L. Xu, X. H. Li et al., "A study of the concrete continuous girder bridge shaking table test considering the sliding of laminated rubber bearings," Vibration and Shock, vol. 36, no. 12, pp. 68-74, 2017.

[12] Y. Itoh, A. Yazawa, T. Kitagawa et al., "Study on environmental durability of rubber bearing for bridges," IABSE Symposium Report International Association for Bridge and Structural Engineering, vol. 86, no. 11, pp. 137-143, 2002.

[13] M. H. Zhou and B. X. Ge, "On the service lifetime of rubber bearing and countermeasures of application for highway bridges," China Civil Engineering Journal, vol. 38, no. 6, pp. 92-96, 2005.

[14] Y. Watanabe, A. Kato, G. Yoneda et al., "Aging effects of forty years old laminated rubber bearings," in Proceedings of the 1st Aseismic and Vibration-Resist Colloquium, pp. 439-446, Japan Society of Civil Engineers, Tokyo, Japan, 1996.

[15] R. I. Skinner, W. H. Robinson, and G. H. McVerry, An Introduction to Seismic Isolation, John Wiley \& Sons, Chichester, UK, 1993.

[16] W. G. Liu, Z. R. Li, F. L. Zhou et al., "Various dependence and duration properties of low stiffness rubber bearings," Earthquake Engineering and Engineering Vibration, vol. 22, no. 6, pp. 115-121, 2002. 
[17] P. H. Mott and C. M. Roland, "Aging of natural rubber in air and seawater," Rubber Chemistry and Technology, vol. 74, no. 1, pp. 79-88, 2001.

[18] K. Ab-Malek and A. Stevenson, "The effect of 42 Year immersion in sea-water on natural rubber," Journal of Materials Science, vol. 21, no. 1, pp. 147-154, 1986.

[19] R. P. Brown and T. Butler, Natural Ageing of Rubber: Changes in Physical Properties over 40 Years, iSmithers Rapra Publishing, Shrewsbury,UK, 2000.

[20] R. P. Brown, T. Butler, and S. W. Hawley, Ageing of Rubber: Accelerated Weathering and Ozone Test Results, iSmithers Rapra Publishing, Shrewsbury,UK, 2001.

[21] R. P. Brown, T. Butler, and S. W. Hawley, Ageing of Rubber: Accelerated Heat Ageing Test Results, iSmithers Rapra Publishing, Shrewsbury,UK, 2001.

[22] I. Yoshito, H. Gu, S Kazuya et al., "Experimental investigation on ageing behaviors of rubbers used for bridge bearings," Doboku Gakkai Ronbunsyun, vol. 62, no. 1, pp. 17-31, 2006.

[23] M. Kato, Y. Watanabe, and G. Yoneda, "Investigation of ageing effects for laminated rubber bearings of Pelham bridge," in Proceedings of 11th World Conference on Earthquake Engineering, Acapulco, Mexico, June 1996.

[24] Q. Han, W. G. Liu, and X. L. Du, "Experimental study on the vertical performance of rubber bearing in compression shear deformation state," East China Highway, vol. 151, no. 1, pp. 44-47, 2005.

[25] X. L. Du, Q. Han, and W. G. Liu, "Study on the mechanical properties of square multi-lead core rubber bearings," Earthquake Engineering and Engineering Vibration, vol. 26, no. 2, pp. 125-130, 2006.

[26] W. G. Liu, Q. R. Yang, and F. L. Zhou, "Experimental study on the temperature-related performance of natural rubber vibration isolation bearings," Journal of Guangzhou University, vol. 6, no. 1, pp. 51-56, 2002.

[27] I. V. Kalpakidis and M. C. Constantinou, "“Effects of heating on the behavior of lead-rubber bearings, 1: theory"' Journal of Structural Engineering, vol. 135, no. 11, pp. 1440-1449, 2009.

[28] I. V. Kalpakidis and M. C. Constantinou, "'Effects of heating on the behavior of lead-rubber bearings, 2: verification of theory"' Journal of Structural Engineering, vol. 135, no. 11, pp. 1450-1461, 2009.

[29] Y. Takenaka, A. Kondo, E. Takaoka et al., "Experimental study on heat-mechanics interaction behavior of laminated rubber bearings," Journal of Structural and Construction Engineering, vol. 646, no. 74, pp. 2245-2253, 2009.

[30] H. S. Gu and Y. ltoh, "Aging Be haviour of natural rubber and high damping rubber materials used in bridge rubber bearings," Advances in Structural Engineering, vol. 6, no. 13, pp. pp1105-1113, 2010.

[31] H. S. Gu and Y. ltoh, "Aging behaviors of natural rubber in isolation bearings," Advanced Materials Research, vol. 163, no. 4, pp. 3343-3347, 2011.

[32] H.-W. Chou, J.-S. Huang, and J. S. Huang, "Fatigue life prediction for circular rubber bearings subjected to cyclic compression," Journal of Applied Polymer Science, vol. 123, no. 4, pp. 2194-2203, 2012.

[33] H. Chou, S. Wei, and H. Jong-Shin, "Effects of thermal aging on fatigue of carbon black-reinforced EPDM rubber," Journal of Applied Polymer Science, vol. 103, no. 2, pp. 32-43, 2007.

[34] Gb20688.3-2007, Rubber Bearings Part 3: Elastomeric Seismicprotection Isolators for Buildings, China standard publishing house, Beijing, China, 2007.
[35] Edited by Japan Society of architecture, Recommendation for the Design of Base Isolated Buildingspp. 110-140, Earthquake Press, Beijing, China, 3rd ed. edition, 2006.

[36] Y. M. Li, Y. H. Ma, and G. F. Zhao, "Study on the aging time variation law of mechanical properties of natural rubber seismic isolation bearings for offshore bridges considering size effect," World Earthquake Engineering, vol. 36, no. 4, pp. 169-176, 2020.

[37] Y. M. Li, Y. H. Ma, G. F. Zhao et al., "Experimental study on the effect of alternating aging and sea corrosion on laminated natural rubber bearing's tension-shear property," Journal of Rubber Research, vol. 18, no. 4, pp. 1-11, 2020.

[38] R. Mooney, "A theory of large elastic deformation," Journal of Applied Physics, vol. 11, no. 4, pp. 582-592, 1940.

[39] G. Marckmann, E. Verron, L. Gornet et al., "A theory of network alteration for the Mullins effect," Journal of the Mechanics and Physics of Solids, vol. 50, no. 4, pp. 2011-2028, 2002.

[40] M. C. Boyce and E. M. Arruda, "Constitutive models of rubber elasticity: a review," Rubber Chemistry and Technology, vol. 73, no. 3, pp. 504-523, 2000.

[41] L. R. G. Treloar, "The elasticity of a network of long-chain molecules. I," Rubber Chemistry And Technology, vol. 16, no. 4, pp. 746-751, 1943.

[42] R. S. Rivlin, "Large elastic deformation of isotropic materials: I. Fundamental concepts, II. Some uniqueness theories for pure homogeneous deformations," Philosophical Transactions of the Royal Society of London,Series A, vol. 240, no. 4, pp. 459-508, 1948.

[43] Y. H. Ma, Y. M. Li, G. F. Zhao et al., "Study on the timevarying law of mechanical properties of rubber seismic isolation bearings based on the effect of thermal aging," Earthquake Engineering and Engineering Vibration, vol. 37, no. 5, pp. 38-44, 2017.

[44] Y. M. Li, Y. H. Ma, J. R. Luo et al., ““'The effect of aging on the material constant of the rubber isolator's constitutive model Mooney-Rivlin"' Vibration and Shock, vol. 35, no. 16, pp. 164-169, 2016.

[45] Ministry of Communications of the People's Republic of China, Series of Elastomeric Pad Bearings for Highway Bridges, China, Beijing, China, 2006.

[46] Ministry of Transport of the People's Republic of China, Specifications for Design of Highway Reinforced Concrete and Prestressed Concrete Bridges and Culverts, Beijing, China, 2018. 